\title{
Yield Curve and Financial Uncertainty: Evidence Based on US Data*
}

\author{
Efrem Castelnuovo \\ University of Melbourne
}

June 5, 2019

\begin{abstract}
How does the yield curve respond to a jump in financial uncertainty? We address this question by conducting a local projections analysis with US monthly data, period: 1962-2018. The state-of-the-art financial uncertainty measure proposed by Ludvigson, $\mathrm{Ma}$, and $\mathrm{Ng}(2019)$ is found to predict movements in interest rates of the entire US yield curve. Both ends of the yield curve respond negatively and significantly. The response of the short end of the yield curve is found to be stronger than that of the long end, i.e., a financial uncertainty shock causes a temporary steepening of the yield curve. This result is consistent, among other interpretations, with medium-term expectations of a recovery in real activity after a financial uncertainty shock.
\end{abstract}

Keywords: Financial uncertainty shocks, yield curve, local projections, inflation dynamics, output growth.

JEL codes: C22, E32, E52.

*We thank Martin Andreasen, Giovanni Caggiano, and especially Giovanni Pellegrino for valuable comments. Financial support by the Australian Research Council via the Discovery Grant DP160102281 is gratefully acknowledged. Authors's contacts: efrem.castelnuovo@unimelb.edu.au .

This is the author manuscript accepted for publication and has undergone full peer review but has not been through the copyediting, typesetting, pagination and proofreading process, which may lead to differences between this version and the Version of Record. Please cite this article as doi: $10.1002 /$ aere. 12341

This article is protected by copyright. All rights reserved. 


\section{Introduction}

How does the yield curve respond to changes in financial uncertainty? This paper addresses this question by estimating the response of a battery of interest rates of US Government bonds having different maturity over the period 1962-2018. We use local projections à la Jord (2005) to produce the impulse responses of such interest rates to a jump in the state-of-the art financial uncertainty measure recently proposed by Ludvigson, Ma, and Ng (2019). We find financial uncertainty to negatively and significantly impact all the elements of the term structure we consider. Talking about maturities, we find a stronger response of the short end of the term structure. The peak response of the 3 -month interest rate is found to be close to -0.4 percentage points, while that of the 10 -year yield is estimated to be about -0.2 percentage points to a jump in uncertainty (the size of the jump being one standard deviation). The positive slope of the yield curve conditional on a jump in uncertainty is documented to be relatively robust over the 5-year horizon we consider when we compute our impulse responses. We interpret such a slope as being consistent with expectations of future inflation and, above all, future output recovery after the shock. Interestingly, when extending our analysis to study the macroeconomic response to a financial uncertainty shock, we find a positive response of inflation in the short run, and a negative response of output growth which peaks shortly before one year, then rebounds, and temporarily becomes positive 3 years after the shock.

This study is related to the burgeoning literature on the effects of uncertainty shocks that has known a renaissance for the last ten years since the paper by Bloom (2009). Surveys have been offered by Bloom (2014), Bloom (2017), Castelnuovo, Lim, and Pellegrino (2017), and Castelnuovo (2019). Different measures of uncertainty have been proposed, and there is an on-going discussion on what measure(s) of uncertainty one should consider to identify uncertainty shocks. ${ }^{1}$ Ludvigson, Ma, and Ng (2019) construct measures of financial, macroeconomic, and real uncertainty with a data-rich approach developed by Jurado, Ludvigson, and $\mathrm{Ng}$ (2015). They find evidence supporting the role of financial uncertainty as a driver of the business cycle, while macroeconomic uncertainty is

${ }^{1}$ Proxies for conceptually different uncertainty measures have been constructed by using, among others, keywords in newspapers (Alexopoulos and Cohen (2015), Baker, Bloom, and Davis (2016)), forecast disagreement (Bachmann, Elstner, and Sims (2013), Sheen and Wang (2019)), real GDP forecast errors (Rossi and Sekhposyan $(2015,2016)$ ), forecast errors of several macroeconomic and financial indicators (Carriero, Clark, and Marcellino (2018b)), Bloomberg forecasts (Scotti (2016)), interest rate data (Mumtaz and Zanetti (2013), Creal and Wu (2017) and Istrefi and Mouabbi (2017)), and Google Trends data (Castelnuovo and Tran (2017)).

This article is protected by copyright. All rights reserved. 
found to be endogenous and act as a magnifier of the effects of other shocks. Angelini, Bacchiocchi, Caggiano, and Fanelli (2019) do not reject the hypothesis that both financial and macroeconomic uncertainty are drivers of the business cycle (for similar results, see Angelini and Fanelli (2019)), while Carriero, Clark, and Marcellino (2018a) point instead to macroeconomic uncertainty as containing information on shocks driving the business cycle. We see the relationship between the financial side of uncertainty and the term structure of interest rates as a natural one. At the very least, the results documented in this paper can be seen as correlations that structural dynamic stochastic general equilibrium (DSGE) models should aim at replicating.

Our study connects with different strands of the literature. First, it relates to the papers that focus on financial uncertainty and their effects on the macroeconomic environment (Bloom (2009), Caggiano, Castelnuovo, and Groshenny (2014), Carriero, Mumtaz, Theodoridis, and Theophilopoulou (2015), Leduc and Liu (2016), Basu and Bundick (2017)). This literature has focused either on (empirical and/or theoretical) frameworks where term structure data are not explicitly modeled. Differently, our paper focuses on the response of the yield curve to financial uncertainty. Second, our paper is linked to those investigating the relationship between uncertainty and monetary policy (Eickmeier, Metiu, and Prieto (2016), Aastveit, Natvik, and Sola (2017), Pellegrino (2018), Pellegrino (2019), and Castelnuovo and Pellegrino (2018)). Our findings are consistent with the "risk-management hypothesis" put forth by Greenspan (2004), i.e., the impact of (different forms of) uncertainty on the US monetary policy decision making. Taylorrule based investigations considering proxies for risk have been proposed by Castelnuovo (2003), Castelnuovo (2007), Evans, Fisher, Gourio, and Krane (2015), Caggiano, Castelnuovo, and Nodari (2018), Caldara and Herbst (2018), and Ponomareva, Sheen, and Wang (2019); quantile-regression frameworks linking policy rates to risk have been estimated by Giglio, Kelly, and Pruitt (2016); nonlinear VARs connecting these two concepts have been estimated by Caggiano, Castelnuovo, and Nodari (2019). Our paper confirms, with a different empirical technique such as local projections, that the response of the short-end of the term structure is indeed consistent with the risk-management hypothesis postulated by Greenspan (2004). Third, our reduced-form empirical paper corroborates findings put forth by authors working with structural nonlinear models that acknowledge a role for risk to understand the term premia (Rudebusch and Swanson (2008), Andreasen (2012), Rudebusch and Swanson (2012), Andreasen, Fernndez-Villaverde, and Rubio-Ramrez (2017), Andreasen (2019), Bianchi, Kung, and Tirskikh (2019)). To some extent, it also connects with models studying the relationship between the long end

This article is protected by copyright. All rights reserved. 
of the term structure and monetary policy (Kulish (2007)). While these contributions hinge upon micro-founded theoretical frameworks, our empirical investigation employs a minimum set of assumptions and, therefore, provides a more "data-driven" answer to the question: "What happens to the yield curve when (financial) uncertainty shocks hits the economy?".

The next Section presents the data employed in this analysis and the empirical framework we use to produce our impulse responses. Section 3 documents our empirical findings. Section 4 concludes.

\section{T 2 Data and empirical model}

Data. We work with interest rates on Treasury Bills at different maturities, i.e., 3 and 6 months, and 1, 5, and 10-year ahead. To maximize the number of monthly observations in our sample, the first two interest rates are secondary market rates, while the other three are constant maturity rates. ${ }^{2}$ Turning to the measure of financial uncertainty, we work with the one recently proposed by Ludvigson, Ma, and Ng (2019). In short, such a measure is constructed by modeling the common variation of the unpredictable components of 148 financial series, where the unpredictable component of each series is computed by performing a one-step ahead forecasting exercise. Finally, we also consider the year-on-year annualized growth rate of inflation and industrial production to capture the stance of the business cycle and its effects on the yield curve. All data used in this paper are downloadable from the Federal Reserve of St. Louis' website, except for the measure of financial uncertainty, which is available at Sydney Ludvigson's website https://www.sydneyludvigson.com/ .

Figure 1 plots the time series of the interest rates and the financial volatility measure we work with. As one can see from the upper panel, all interest rates display a clear upward trend from the early 1960s until the early 1980s. Then, a change in sign occurs, and a negative trend is followed by all rates until the end of the sample, with interest rates recording historically low values during and after the 2007-09 great recession. The low frequency component of these rates is likely to be related to the evolution of the trend inflation process estimated by many authors (Ireland (2007), Cogley and Sbordone (2008), Cogley, Primiceri, and Sargent (2010), Castelnuovo (2010b), Castelnuovo

${ }^{2}$ Data source: Federal Reserve Bank of St. Louis' database. The 3 and 6-month constant maturity rate series are available from 1982M1. The correlation between the series we use (3 and 6-month secondary market rate) and the constant maturity rate ones is basically one.

This article is protected by copyright. All rights reserved. 
(2012a), Castelnuovo, Greco, and Raggi (2014)). The change in the slope of such process could be possibly related to the shift to a more aggressive systematic monetary policy occurred when Paul Volcker became chairman of the Federal Reserve in August 1979 (Clarida, Gal, and Gertler (2000), Lubik and Schorfheide (2004), Boivin and Giannoni (2006), Coibion and Gorodnichenko (2011), Coibion and Gorodnichenko (2012), Castelnuovo and Fanelli (2015), and Arias, Ascari, Branzoli, and Castelnuovo (2019)). Such a change is likely to have had effects also on short-run inflation expectations (Castelnuovo and Surico (2010), Castelnuovo (2010a), Castelnuovo (2012b)). In spite of this common trend, differences may be noted in the level and volatility of longer term rates ( 5 and 10-year) with respect to those whose maturity is 1-year or lower. In particular, the interest rates of the latter group exhibit higher volatility, lower values in a number of cases, and hit and remain at the zero lower bound in the 2008-2015 period. This difference has already been noted by, among others, Swanson and Williams (2014), who point out that the Federal Reserve was probably not very constrained by the zero lower bound given its ability to influence longer term rates during and after the great recession (for contrasting views on this matter, see Caggiano, Castelnuovo, and Pellegrino (2017) and Swanson (2019)). Turning to financial uncertainty (Figure 1, bottom panel), one can clearly identify swings in the series, with the two highest peaks corresponding to the black Monday in October 1987 and the acceleration of the financial crisis triggered by the collapse of Lehman Brothers in September 2008. Differently from the interest rates commented above, financial uncertainty does not display any clear trend.

Empirical model. For $h=0, \ldots, H$, we estimate the following framework:

$$
R_{t+h}^{j}=c_{h}+\beta_{h} u n c_{t}+\gamma_{h} z_{t}+\varepsilon_{t+h}
$$

where $R_{t+h}^{j}$ is the annual yield on a bond with maturity $j, j=3$ months, 6 months, 1 year, 5 years, and 10 years; $u n c_{t}$ is the proxy for financial uncertainty we use, i.e., the financial uncertainty measure estimated by Ludvigson, Ma, and Ng (2019) and conditional on a forecasting horizon equal to one month; $z_{t}$ is a set of controls including the year-on-year growth rates of CPI inflation and industrial production, as well as the lagged values of all interest rates we work with (one lag per each interest rate).

Local projections (LP) are predictive models forecasting $R_{t+h}^{j}$ directly with the covariates on the right-hand side of eq. (1). Hence, all estimated coefficients are indexed by $h$, which is the horizon considered when running the regression above. In particular, the coefficient $\beta_{h}$ captures the response of $R_{t+h}^{j}$ at time $t+h$ to the shock at time $t$. This implies that one can construct the impulse responses as a sequence of the coefficients

This article is protected by copyright. All rights reserved. 
$\beta_{h}$, which are estimated in a series of single regressions of interest for each horizon. Differently, VARs - often used to compute impulse responses to identified structural shocks - provide the econometrician with the parameters for $h=0$. Then, one constructs the impulse response functions by employing the estimated VAR dynamic structure. (For a formal comparison between VAR and LP impulse responses, see Plagborg-Mller and Wolf (2018).) Before running our regressions, we standardize unc to have zero mean and variance equal to one. This enables us to interpret the percentage change response of $R_{t+h}^{j}$ captured by $\beta_{h}$ as the response to a one-standard deviation jump in uncertainty. ${ }^{3}$ We estimate eq. (1) with ordinary least squares. One implication of Jordà's (2005) method is that the error terms $\varepsilon_{t+h}$ are serially correlated due to the successive leading of the dependent variable. Hence, we use the Newey and West (1987) correction for our standard errors.

\section{Findings}

Figure 2 plots the impulse responses of the five interest rates we model to an uncertainty shock. Financial uncertainty is found to have a negative and significant impact on the whole spectrum, with a quantitatively stronger effect on the short end of the yield curve (peak response: -0.4 percentage points) than the long end (peak response: -0.2 percentage points). This implies that, at least in this sample, an increase in uncertainty is followed by a temporarily steeper yield curve. Interestingly Figure 3 confirms that the steepening of the yield curve following a (mathematically) positive change in financial uncertainty occurs over most of the horizons we consider in our analysis, although - starting after about 2 years - it gets gradually less important from a quantitative standpoint for longer horizons (a sign that the effects of the shock are temporary). Importantly, the impact of uncertainty on interest rates at various maturities is present despite of the fact that we control for the role played by inflation, output growth, and the past values of the whole battery of interest rates. Note that the steepening of the yield curve is robust to excluding the zero lower bound period from our sample (regressions that consider the 1962M1-2008M6 sample).

\footnotetext{
${ }^{3}$ Bivariate VARs estimated with financial uncertainty and (alternatively) each one of the interest rates considered here point to evidence in favor of Granger causality going from financial uncertainty to all such rates (at least at a $10 \%$ significance level), while the opposite is not true for the 3-month, 6-month, and 10-year rates, although evidence of reverse causality is found for the 1-year and 5-year rates. The main result of this paper, i.e., the steepening of the yield curve after an uncertainty shock, is robust to discarding the results related to the 1-year and 5-year rates.
}

This article is protected by copyright. All rights reserved. 
Why do yields decrease? The negative response of yields can be driven by different channels. First, an increase in uncertainty reduces aggregate consumption via precautionary savings. Hence, resources switch from consumption to savings, and it may very well the case that, in a risky environment, short term Government bonds (perceived as less risky) receive most of this increase in savings. Hence, given the inverse relationship between bond prices and yields, the latter decrease. Second, uncertainty shocks are typically recessionary. Hence, at least in normal times, the response by monetary policy authorities is that of slashing the policy rate. Given the connection between short and long rates via the term structure, all rates decline. Third, uncertainty surrounding the economic outlook per se can lead to a more cautions monetary policy if the central bank acts as a risk-manager and systematically responds to fluctuations in uncertainty.

Why does the curve get steeper? One possibility is that, after an uncertainty shock, investors decide to shorten the maturity of the financial assets they hold in their portfolio to reduce portfolio risks and avoid bearing a suboptimally high risk/yield ratio. Bianchi, Kung, and Tirskikh (2019) estimate a dynamic stochastic general equilibrium framework in which both second moment shocks to household's discount factor and second moment technology shocks can have first moment effects on the business cycle and the yield curve. In line with our findings (which are obtained with a reduced-form, "restrictionfree" approach), both type of shocks lead to a temporary steepening of the yield curve. Their interpret such a change in the slope of the yield curve with the lower degree of insurance against the inflation risk provided by long term bonds. Other models delivering a steepening of the yield curve after an uncertainty shock for similar reasons are Andreasen (2012), Amisano and Tristani (2019), and Andreasen (2019). An undergraduate textbook-type of interpretation points to inflation and output expectations formed by rational agents. To the extent that a Taylor rule-type of link between the policy rate and macroeconomic indicators such as inflation and output growth exists, it may be the case that agents expect future rates to be higher that current ones because of an expected recovery of inflation and/or output growth in the medium run. We investigate this last hypothesis by extending our analysis to study the macroeconomic response to a financial uncertainty shock.

Figure 4 shows the response of inflation and output growth (proxied by the growth rate of industrial production) to an upward variation in financial uncertainty. ${ }^{4}$ Inflation immediately goes up after an uncertainty shock. If this response influences short run

${ }^{4}$ These responses are computed by manipulating eq. (1) to have inflation (or output growth) on the left hand side and the lag of inflation (or output growth) on the right hand side to avoid having the very same variable with the very same timing on both sides of the equation when $h=0$.

This article is protected by copyright. All rights reserved. 
expectations more than long run ones, then expected inflation is not necessarily the explanation for the steepening of the yield curve. Differently, the response of output is negative, significant, and persistent, with a peak around 1 year. Then, output recovers, and indeed overshoots, peaking again after about 3 years before going back to its steady state. The timing of this response seems to be more consistent with that of mediumterm expectations of a future recovery being behind the more moderate drop of long term rates (as opposed to short term ones) after a financial uncertainty shock.

As a side note, the responses of inflation and output depicted in Figure 4 are also interesting from a macroeconomic standpoint. These responses place the financial uncertainty shock under the category "supply shocks", i.e., such a shock is found to move inflation and output in opposite directions. Interestingly, this result is not a solid one in the literature. Leduc and Liu (2016) find that both inflation and output temporarily decrease after a financial uncertainty shock, which they classify as a "demand" one. Fasani and Rossi (2018) work with a slightly modified version of Leduc and Liu's (2016) model in which the policy response to an uncertainty shock is gradual due to an interest rate smoothing motive. They find that this modification of the Leduc-Liu framework changes the sign of the response of inflation and leads to classify the uncertainty shock as a supply shock. Moreover, from firms' standpoint, it is optimal to increase prices in response to an increase in uncertainty when prices are sticky, because firms want to avoid signing contracts with suboptimally low prices when some possible (a priori uncertain) future realizations of technology or demand occur (realizations that, with too low prices, would lead to a loss in profits) (Fernndez-Villaverde, Guerrón-Quintana, Kuester, and Rubio-Ramírez (2015)).

Obviously, understanding the nature of uncertainty shocks is relevant from a policy standpoint because of the different trade-offs implied by supply and demand shocks. Focusing on the response of output in Figure 4, we note the "drop-rebound-overshoot" type of dynamics originally documented by Bloom (2009). He interprets this evidence with a model in which the reallocation of resources from low to high-productive firms after a firm-specific technology-related uncertainty shock leads to a temporary overshoot of the level of output (differently, here we have an overshoot of the growth rate). ${ }^{5}$ Evidence in favor of such a dynamic behavior by real activity indicators in presence of an uncertainty shock can also be found in Caggiano, Castelnuovo, and Groshenny (2014). Before moving to our conclusions we notice what follows. While a decrease in the short

${ }^{5}$ The persistence of the output growth rate (as well as that of the inflation rate) is in part due to the fact that we are using year-on-year rates, i.e., 12-term moving averages of monthly rates.

This article is protected by copyright. All rights reserved. 
term rates is a very likely event after an uncertainty shock given the monetary policy response to a fall in output, a decrease in the long term ones is not that obvious a priori. In fact, there are contrasting effects to consider when it comes to predicting the response of the long end of the yield curve. On the one hand, a monetary policy easing tends to push the long end of the curve downwards. On the other hand, a shortening of financial positions by investors after the shock exerts a upward pressure on the yields on long term bonds. Hence, we see our result on the negative change of all yields (long term ones included) as an interesting stylized fact modelers should consider when building up structural frameworks featuring uncertainty and the term structure.

\section{Conclusions}

This short paper has estimated the link between changes in financial uncertainty and the yield curve using a sample of US monthly data. The main empirical findings are: i) the yield curve responds negatively and significantly to an uncertainty shock; ii) the short end of the curve is more responsive than the long-end, i.e., after an uncertainty shock, the slope of the yield curve temporarily increases; iii) such an increase is confirmed by most of the horizons considered by our predictive exercise; iv) we find evidence consistent with a possible link between the rotation of the yield curve mentioned above and the response of output growth to a financial uncertainty shock

Our analysis has just scratched the surface of the relationship between uncertainty and the term structure. First, it would be interesting to check if these results are robust to using data of other countries. For instance, Baker, Bloom, and Davis (2016) find uncertainty shocks to trigger a macroeconomic response in a variety of industrialized economies. It would be useful to understand if this is true also for the term structure of interest rates, and what the effect on the slope of the yield curve is. Given the role played by forecasts on the economic outlook for the response and the slope of the curve, one could speculate that countries with more credible central banks (perhaps thanks to the official adoption of the inflation targeting regime) could feature different responses than countries whose monetary policy is more surrounded by uncertainties. Moreover, the different business cycle effects found by some researchers to changes in the same concept of uncertainty across different countries (e.g., Castelnuovo and Tran (2017)) could also be related to different monetary policy stances (e.g., the presence of the ZLB in some countries, but not in others). Related to this issue, many researchers have recently focused on the effects of global uncertainty (for a survey and some novel empirical results

This article is protected by copyright. All rights reserved. 
based on the global financial uncertainty index developed by Caggiano and Castelnuovo (2019), see Castelnuovo (2019)). It would interesting to understand if movements in the term structure are mostly due to domestic uncertainty or, differently, to uncertaintytriggering global events. Possibly, cross-country differences based on the different degree of trade and financial openness could emerge. Third, this piece has assumed that the transmission from financial uncertainty shocks to the term structure of interest rate in the US is linear. While being a convenient assumption, recent research has documented nonlinearities in the macroeconomic impact of exogenous changes in uncertainty due to a different stance of the business (Caggiano, Castelnuovo, and Groshenny (2014), Nodari (2014), Caggiano, Castelnuovo, and Figueres (2017), Caggiano, Castelnuovo, and Nodari (2019), Caggiano, Castelnuovo, and Figueres (2019), Andreasen, Caggiano, Castelnuovo, and Pellegrino (2019)) or financial (Alessandri and Mumtaz (2018)) cycle. Obviously, it would be interesting to understand if these nonlinearities play a role also for the response of the yield curve to an uncertainty shock. Finally, this study has assumed that changes in financial uncertainty are exogenous to movements in the term structure of interest rates. As anticipated in the Introduction, recent research by Ludvigson, Ma, and $\mathrm{Ng}$ (2019), Angelini, Bacchiocchi, Caggiano, and Fanelli (2019), and Angelini and Fanelli (2019) supports this hypothesis. However, developing instruments to minimize the risk of getting spurious results from endogeneity-prone regressions is clearly an important avenue for future research. For a first attempt in this sense, see Piffer and Podstawski (2018).

\section{References}

Aastveit, K. A., G. J. Natvik, and S. Sola (2017): "Economic Uncertainty and the Influence of Monetary Policy," Journal of International Money and Finance, 76, $50-67$.

Alessandri, P., And H. Mumtaz (2018): "Financial Regimes and Uncertainty Shocks," Journal of Monetary Economics, forthcoming.

Alexopoulos, M., And J. Cohen (2015): "The power of print: Uncertainty shocks, markets, and the economy," International Review of Economics and Finance, 40(C), $8-28$.

Amisano, G., and O. Tristani (2019): "Uncertainty shocks, monetary policy and long-term interest rates," ECB Working Paper No 2279.

This article is protected by copyright. All rights reserved. 
Andreasen, M., G. Caggiano, E. Castelnuovo, and G. Pellegrino (2019): "Uncertainty-Driven Comovements in Booms and Busts: A Structural Intepretation," Aarhus University, Monash University, and University of Melbourne, in progress.

Andreasen, M. M. (2012): "On the Effects of Rare Disasters and Uncertainty Shocks for Risk Premia in Non-Linear DSGE Models," Review of Economic Dynamics, 15(3), 295-316.

(2019): "Explaining Bond Return Predictability in an Estimated New Keynesian Model," CREATES Research Paper 2019-11.

Andreasen, M. M., J. Fernndez-Villaverde, and J. F. Rubio-Ramrez (2017): "The Pruned State-Space System for Non-Linear DSGE Models: Theory and Empirical Applications," Review of Economic Studies, forthcoming.

Angelini, G., E. Bacchiocchi, G. Caggiano, and L. Fanelli (2019): "Uncertainty Across Volatility Regimes," Journal of Applied Econometrics, 34(3), 437-455.

Angelini, G., and L. FAnElli (2019): "Exogenous uncertainty and the identification of Structural Vector Autoregressions with external instruments," University Ca' Foscari of Venice and University of Bologna, mimeo.

Arias, J. E., G. Ascari, N. Branzoli, and E. Castelnuovo (2019): "Positive Trend Inflation and Determinacy in a Medium-Sized New-Keynesian Model," International Journal of Central Banking, forthcoming.

Bachmann, R., S. Elstner, and E. Sims (2013): "Uncertainty and Economic Activity: Evidence from Business Survey Data," American Economic Journal: Macroeconomics, 5(2), 217-249.

Baker, S., N. Bloom, and S. J. Davis (2016): "Measuring Economic Policy Uncertainty," Quarterly Journal of Economics, 131(4), 1539-1636.

BAsu, S., AND B. Bundick (2017): "Uncertainty Shocks in a Model of Effective Demand," Econometrica, 85(3), 937-958.

Bianchi, F., H. Kung, And M. Tirskikh (2019): "The Origins and Effects of Macroeconomic Uncertainty," Duke University and London Business School, mimeo.

Bloom, N. (2009): "The Impact of Uncertainty Shocks," Econometrica, 77(3), 623-685.

This article is protected by copyright. All rights reserved. 
(2014): "Fluctuations in Uncertainty," Journal of Economic Perspectives, $28(2), 153-176$.

Bloom, N. (2017): "Observations on Uncertainty," Australian Economic Review, 50(1), 79-84.

Boivin, J., And M. Giannoni (2006): "Has Monetary Policy Become More Effective?," Review of Economics and Statistics, 88(3), 445-462.

Caggiano, G., and E. Castelnuovo (2019): "Global Uncertainty," Monash University and University of Melbourne, available at https://sites.google.com/site/efremcastelnuovo/.

Caggiano, G., E. Castelnuovo, and J. M. Figueres (2017): "Economic Policy Uncertainty and Unemployment in the United States: A Nonlinear Approach," Economics Letters, 151, 31-34.

(2019): "Economic Policy Uncertainty Spillovers in Booms and Busts," Oxford Bulletin of Economics and Statistics, forthcoming.

Caggiano, G., E. Castelnuovo, and N. Groshenny (2014): "Uncertainty Shocks and Unemployment Dynamics: An Analysis of Post-WWII U.S. Recessions," Journal of Monetary Economics, 67, 78-92.

Caggiano, G., E. Castelnuovo, and G. Nodari (2018): "Risk ManagementDriven Policy Rate Gap," Economics Letters, 171, 235-238.

(2019): "Uncertainty and Monetary Policy in Good and Bad Times," available at https://sites.google.com/site/efremcastelnuovo/.

Caggiano, G., E. Castelnuovo, and G. Pellegrino (2017): "Estimating the Real Effects of Uncertainty Shocks at the Zero Lower Bound," European Economic Review, 100, 257-272.

Caldara, D., and E. Herbst (2018): "Monetary Policy, Real Activity, and Credit Spreads: Evidence from Bayesian Proxy SVAR," American Economic Journal: Macroeconomics, 11(1), 157-192.

Carriero, A., T. E. Clark, and M. Marcellino (2018a): "Endogenous Uncertainty," Federal Reserve Bank of Cleveland Working Paper No. 18-05.

This article is protected by copyright. All rights reserved. 
(2018b): "Measuring Uncertainty and Its Impact on the Economy," Review of Economics and Statistics, forthcoming.

Carriero, A., H. Mumtaz, K. Theodoridis, and A. Theophilopoulou (2015): "The Impact of Uncertainty Shocks under Measurement Error: A Proxy SVAR Approach," Journal of Money, Credit and Banking, 47(6), 1223-1238.

Castelnuovo, E. (2003): "Taylor Rules, Omitted Variables, and Interest Rate Smoothing in the US," Economics Letters, 81(1), 55-59.

Castelnuovo, E. (2007): "Taylor Rules and Interest Rate Smoothing in the Euro Area," Manchester School, 75(1), 1-16.

(2010a): "Tracking U.S. Inflation Expectations with Domestic and Global Determinants," Journal of International Money and Finance, 29(7), 1340-1356.

(2010b): "Trend Inflation and Macroeconomic Volatilities in the post-WWI U.S. Economy," North American Journal of Economics and Finance, 21(1), 19-33.

(2012a): "Fitting U.S. Trend Inflation: A Rolling-Window Approach," in Nathan Balke, Fabio Canova, Fabio Milani, and Mark Wynne (eds.): Advances in Econometrics: DSGE Models in Macroeconomics - Estimation, Evaluation, and New Developments, 28, 201-252.

(2012b): "Policy Switch and the Great Moderation: The Role of Equilibrium Selection," Macroeconomic Dynamics, 16(3), 449-471.

(2019): "Domestic and Global Uncertainty: A Brief Survey and Some New Results," mimeo, available at https://sites.google.com/site/efremcastelnuovo/.

Castelnuovo, E., And L. Fanelli (2015): "Monetary Policy Indeterminacy and Identification Failures in the U.S.: Results from a Robust Test," Journal of Applied Econometrics, 30(6), 924-947.

Castelnuovo, E., L. Greco, and D. RagGi (2014): "Policy Rules, Regime Switches, and Trend Inflation: An Empirical Investigation for the U.S.," Macroeconomic Dynamics, 18, 920-942.

Castelnuovo, E., G. Lim, and G. Pellegrino (2017): "A Short Review of the Recent Literature on Uncertainty," Australian Economic Review, 50(1), 68-78.

This article is protected by copyright. All rights reserved. 
Castelnuovo, E., And G. Pellegrino (2018): "Uncertainty-dependent Effects of Monetary Policy Shocks: A New Keynesian Interpretation," Journal of Economic Dynamics and Control, 93, 277-296.

Castelnuovo, E., And P. Surico (2010): "Monetary Policy Shifts, Inflation Expectations and the Price Puzzle," Economic Journal, 120(549), 1262-1283.

Castelnuovo, E., and T. D. Tran (2017): "Google it up! A Google Trends-based Uncertainty Index for the United States and Australia," Economics Letters, 161, 149 153.

Clarida, R., J. Gal, and M. Gertler (2000): "Monetary Policy Rules and Macroeconomic Stability: Evidence and Some Theory," Quarterly Journal of Economics, 115, $147-180$.

Cogley, T., G. E. Primiceri, and T. Sargent (2010): "Inflation-Gap Persistence in the U.S.," American Economic Journal: Macroeconomics, 2(1), 43-69.

Cogley, T., and A. Sbordone (2008): "Trend Inflation, Indexation, and Inflation Persistence in the New Keynesian Phillips Curve," American Economic Review, 98(5), 2101-2126.

Coibion, O., and Y. Gorodnichenko (2011): "Monetary Policy, Trend Inflation and the Great Moderation: An Alternative Interpretation," American Economic Review, 101, 341-370.

(2012): "Why are target interest rate changes so persistent?," American Economic Journal: Macroeconomics, 4(4), 126-162.

Creal, D. D., And C. Wu (2017): "Monetary Policy Uncertainty and Economic Fluctuations," International Economic Review, forthcoming.

Eickmeier, S., N. Metiu, and E. Prieto (2016): “Time-Varying Volatility, Financial Intermediation and Monetary Policy," CAMA Working Paper No. 32/2016.

Evans, C., J. D. M. Fisher, F. Gourio, and S. Krane (2015): "Risk Management for Monetary Policy Near the Zero Lower Bound," Brookings Papers on Economic Activity, Spring, 141-196.

Fasani, S., And L. Rossi (2018): "Are Uncertainty Shocks Aggregate Demand Shocks?," Economics Letters, 167, 142-146.

This article is protected by copyright. All rights reserved. 
Fernndez-Villaverde, J., P. Guerrón-Quintana, K. Kuester, and J. F. Rubio-RAmíRez (2015): "Fiscal Volatility Shocks and Economic Activity," American Economic Review, 105(11), 3352-3384.

Giglio, S., B. Kelly, and S. Pruitt (2016): "Systemic Risk and the Macroeconomy: An Empirical Evaluation," Journal of Financial Economics, 119(3), 457-471.

Greenspan, A. (2004): "Risk and Uncertainty in Monetary Policy," American Economic Review Papers and Proceedings, 94(2), 33-40.

Ireland, P. (2007): "Changes in Federal Reserve's Inflation Target: Causes and Consequences," Journal of Money, Credit and Banking, 39(8), 1851-1882.

Istrefi, K., And S. MouabBi (2017): "Subjective Interest Rate Uncertainty and the Macroeconomy: A Cross-country Analysis," Journal of International Money and Finance, forthcoming.

JorD, O. (2005): "Estimation and Inference of Impulse Responses by Local Projections," American Economic Review, 95(1), 161-182.

Jurado, K., S. C. Ludvigson, and S. NG (2015): "Measuring Uncertainty," American Economic Review, 105(3), 1177-1216.

Kulish, M. (2007): "Should Monetary Policy Use Long-Term Rates?," B.E. Journal of Macroeconomics (Advances), 7(1), 1935-1690.

Leduc, S., AND Z. Liu (2016): "Uncertainty Shocks are Aggregate Demand Shocks," Journal of Monetary Economics, 82, 20-35.

Lubik, T., And F. Schorfheide (2004): “Testing for Indeterminacy: An Application to U.S. Monetary Policy," American Economic Review, 94(1), 190-217.

Ludvigson, S. C., S. MA, And S. NG (2019): "Uncertainty and Business Cycles: Exogenous Impulse or Endogenous Response?," New York University and Columbia University, mimeo.

Mumtaz, H., and F. Zanetti (2013): "The Impact of the Volatility of Monetary Policy Shocks," Journal of Money, Credit and Banking, 45(4), 535-558.

This article is protected by copyright. All rights reserved. 
Newey, W. K., And K. D. West (1987): "A Simple, Positive Semi-Definite, Heteroskedasticity and Autocorrelation Consisten tCovariance Matrix," Econometrica, $55(3), 703-708$.

NodARI, G. (2014): "Financial Regulation Policy Uncertainty and Credit Spreads in the U.S.," Journal of Macroeconomics, 41, 122-132.

Pellegrino, G. (2018): "Uncertainty and the Real Effects of Monetary Policy Shocks in the Euro Area," Economics Letters, 162, 177-181.

(2019): "Uncertainty and Monetary Policy in the US: A Journey into Non-Linear Territory," available at https://sites.google.com/site/giovannipellegrinopg/home.

Piffer, M., And M. Podstawski (2018): "Identifying uncertainty shocks using the price of gold," Economic Journal, 128(616), 3266-3284.

Plagborg-Mller, M., And C. K. Wolf (2018): "Local Projections and VARs Estimate the Same Impulse Responses," Princeton University, mimeo.

Ponomareva, N., J. Sheen, and B. Z. Wang (2019): "Does monetary policy respond to uncertainty? Evidence from Australia," Australian Economic Review, forthcoming.

Rossi, B., And T. Sekhposyan (2015): "Macroeconomic Uncertainty Indices Based on Nowcast and Forecast Error Distributions," American Economic Review Papers and Proceedings, 105(5), 650-655.

Rossi, B., And T. Sekhposyan (2017): "Macroeconomic Uncertainty Indices for the Euro Area and its Individual Member Countries," Empirical Economics, 53(1), 41-62.

Rudebusch, G. D., And E. T. Swanson (2008): "Examining the Bond Premium Puzzle with a DSGE Model," Journal of Monetary Economics, 55, 111-126.

(2012): "The Bond Premium in a DSGE Model with Long-Run Real and Nominal Risks," American Economic Journal: Macroeconomics, 4(1), 105-143.

Scotti, C. (2016): "Surprise and Uncertainty Indexes: Real-Time Aggregation of RealActivity Macro Surprises," Journal of Monetary Economics, 82, 1-19.

This article is protected by copyright. All rights reserved. 
SheEn, J., AND B. Z. WANG (2019): "Understanding Macroeconomic Disagreement," Macquarie University, mimeo.

Swanson, E. T. (2019): "The Federal Reserve Is Not Very Constrainedby the Lower Bound on Nominal Interest Rates," University of California, Irvine, mimeo.

Swanson, E. T., and J. C. Williams (2014): "Measuring the Effect of the Zero Lower Bound on Medium- and Long-Term Interest Rates," American Economic Review, 104(10), 3154-3185.

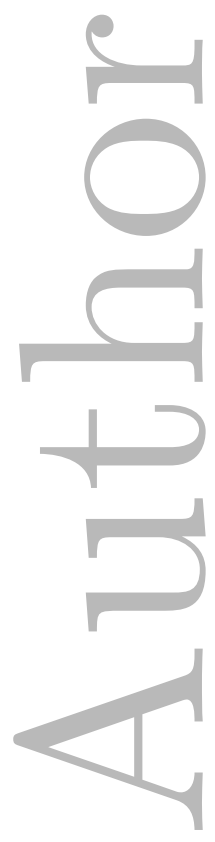

This article is protected by copyright. All rights reserved. 

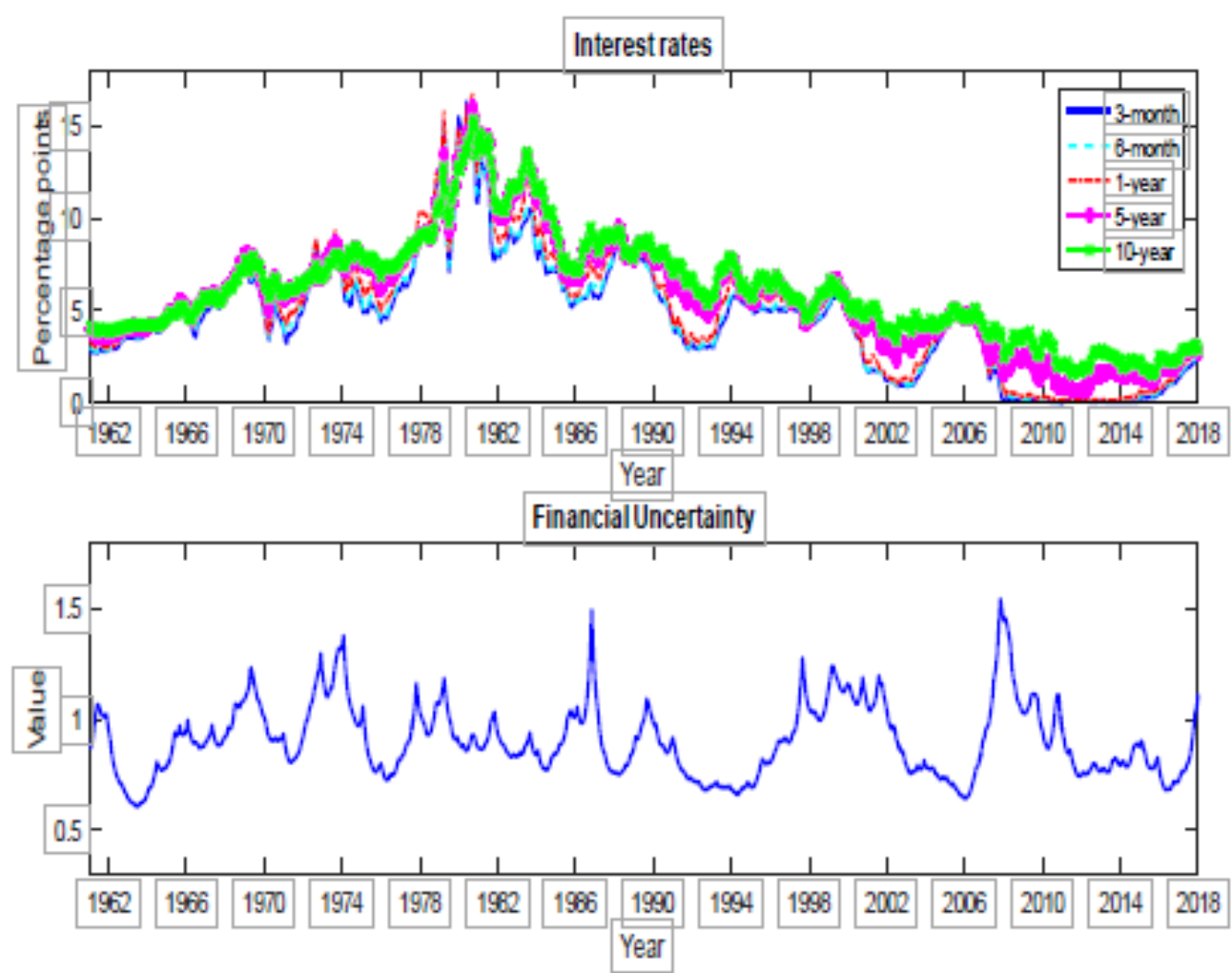

Figure 1: Interest rates and financial volatility. Top panel: Interest rates related to Treasury Bills at different maturity. Bottom panel: Measure of financial volatility by Ludvigston, $\mathrm{Ma}$, and $\mathrm{Ng}$ (2019) (conditional on a forecasting horizon $=1 \mathrm{month}$ ).

This article is protected by copyright. All rights reserved. 

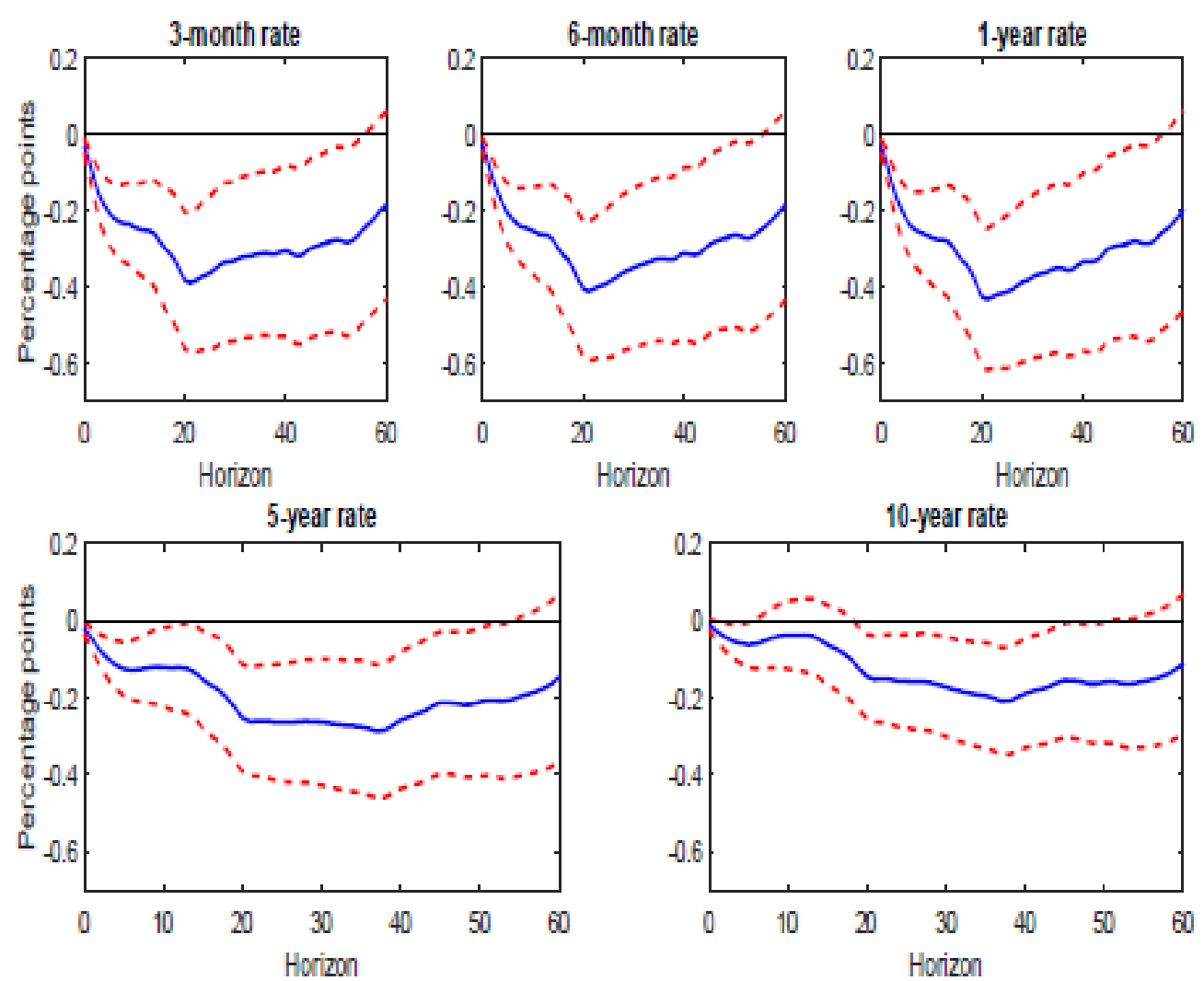

Figure 2: Response of interest rates to a financial uncertainty shock. Measure of financial uncertainty by Ludvigson, $\mathrm{Ma}$, and $\mathrm{Ng}(2019)$ standardized to have zero mean and standard deviation equal to one to interpret the responses above as responses to one-standard deviation shock. $68 \%$ confidence bands identified by dashed red lines.

This article is protected by copyright. All rights reserved. 


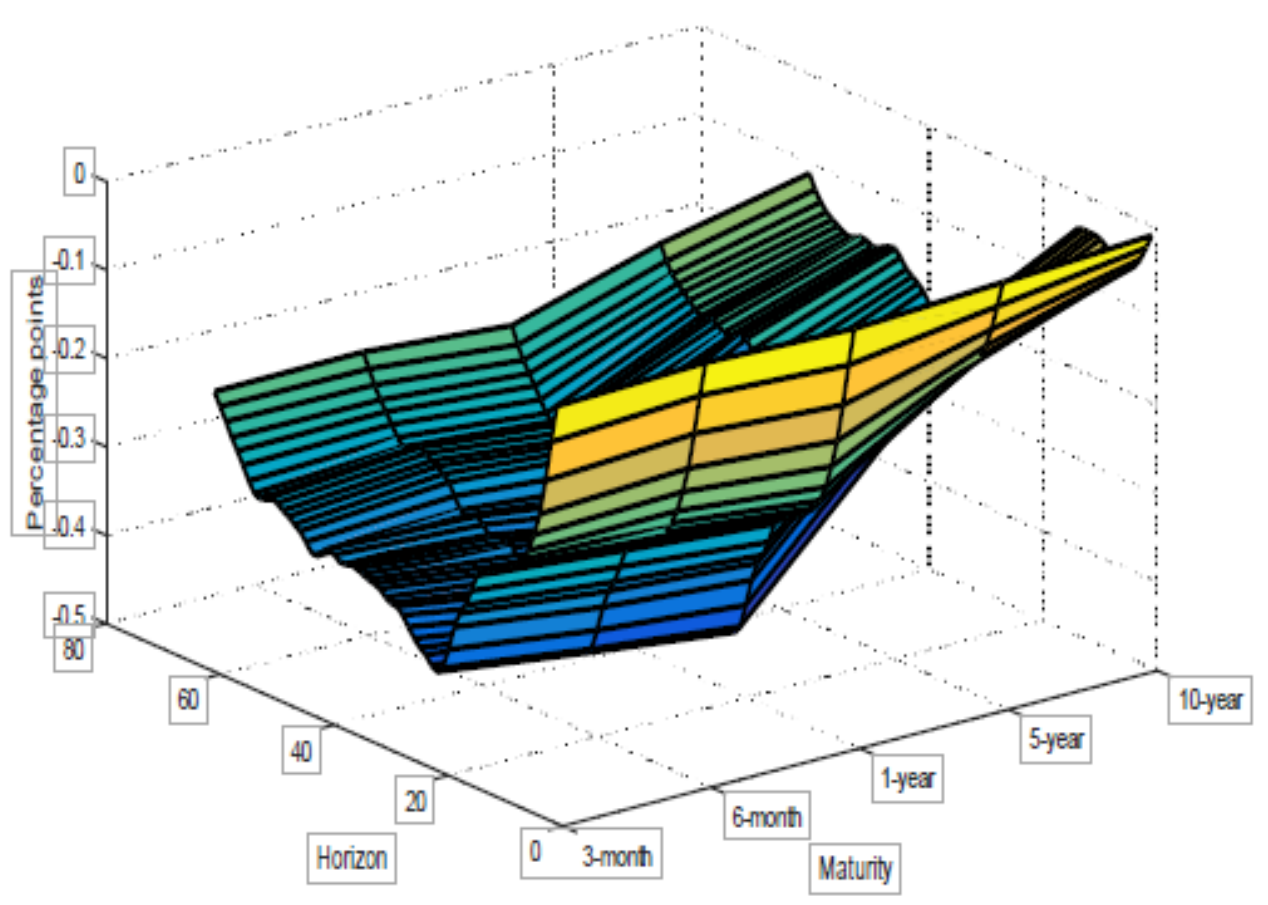

Figure 3: Evolution of the yield curve over different horizons in response to a financial uncertainty shock. Measure of financial uncertainty by Ludvigson, Ma, and $\mathrm{Ng}$ (2019) standardized to have zero mean and standard deviation equal to one to interpret the responses above as responses to one-standard deviation shock.

This article is protected by copyright. All rights reserved. 

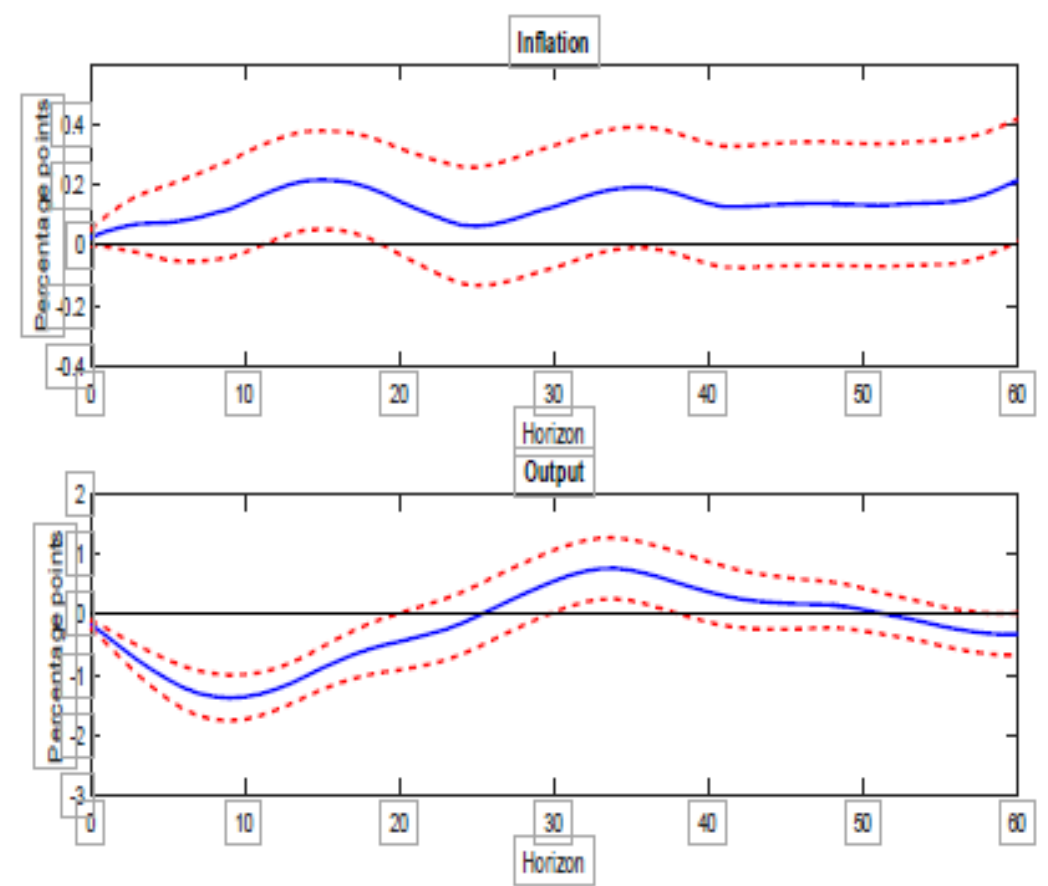

Figure 4: Response of inflation and output to a financial uncertainty shock. Measure of financial uncertainty by Ludvigson, $\mathrm{Ma}$, and $\mathrm{Ng}(2019)$ standardized to have zero mean and standard deviation equal to one to interpret the responses above as responses to one-standard deviation shock. Inflation (output) computed as the percentualized yearly growth rate of the consumer price (industrial production) index. $68 \%$ confidence bands identified by dashed red lines.

his article is protected by copyright. All rights reserved. 


\section{University Library}

\section{- M M I N E R VA A gateway to Melbourne's research publications}

Minerva Access is the Institutional Repository of The University of Melbourne

Author/s:

Castelnuovo, E

Title:

Yield Curve and Financial Uncertainty: Evidence Based on US Data

Date:

2019-09-01

Citation:

Castelnuovo, E. (2019). Yield Curve and Financial Uncertainty: Evidence Based on US Data. The Australian Economic Review, 52 (3), pp.323-335. https:// doi.org/10.1111/1467-8462.12341.

Persistent Link:

http://hdl.handle.net/11343/286910 